\title{
The cost-effectiveness of venous-converted acid-base and blood gas status in pulmonary medical departments
}

This article was published in the following Dove Press journal:

ClinicoEconomics and Outcomes Research

15 December 2010

Number of times this article has been viewed

Lars Oddershede'

Sabrina Storgaard Petersen'

Asgerd Krogh Kristensen ${ }^{2}$

Jan Freddy Pedersen ${ }^{3}$

Stephen Edward Rees'

Lars Ehlers ${ }^{4}$

'Department of Health Science and Technology, Aalborg University, Aalborg, Denmark; ${ }^{2}$ Department of Pulmonary Medicine, Aalborg Hospital Section South, Aalborg, Denmark; ${ }^{3}$ Department of Clinical Biochemistry, Aalborg Hospital Section South, Aalborg, Denmark; ${ }^{4}$ Health Economics and Management, Aalborg University, Aalborg, Denmark

Correspondence: Lars Oddershede Aarestrupsvej 20 I.Tv, 9000 Aalborg, Denmark

Tel +45 40609448

Email lodder07@student.aau.dk
Introduction: The current use of arterial punctures, when obtaining arterial blood gas and acid-base status of patients, are associated with a risk of side effects such as pain and hematoma, and a small risk of more severe complications. This analysis investigated the cost-effectiveness of a new method, where less painful venous-converted tests are used as an alternative to arterial punctures.

Methods: A cost-utility analysis was conducted from the Danish hospital perspective using a Markov model. The model represents the admission of a typical patient suffering from chronic obstructive pulmonary disease to the Department of Pulmonary Medicine, Aalborg Hospital. Evidence of the effect of the venous-converted tests' pain reduction was converted into shortterm gain in quality-adjusted life years (QALYs), using the Danish EuroQol-5 Dimension value set. A Monte Carlo second order simulation of 10,000 hypothetical patients was conducted for a midsized and a small department.

Results: Monte Carlo simulation of the incremental cost-effectiveness ratio (ICER) was dominant for a midsized department, and for a small department the mean was $£ 10,645$ per QALY gained. The scatter plot of ICERs revealed that at a willingness-to-pay (WTP) of $£ 30,000$ per QALY gained, the venous conversion method is $>95 \%$ cost-effective in a midsized department and $51 \%$ in a small department.

Conclusion: It was concluded that the venous conversion method should be applied to hospitals with midsized pulmonary departments, and could be applied to small pulmonary departments if the WTP is sufficient.

Keywords: arterial punctures, cost-utility analysis, Markov model, pain, hematoma

\section{Introduction}

Measurement of arterial blood gas and acid-base status is a helpful and often necessary tool when assessing the state of the acutely ill patient. Arterial punctures, which are considered to be the reference technique for measuring the acid-base status and the gaseous content of the blood, are widely performed in intensive care units and in emergency and pulmonary medicine departments by specially trained staff. In order to monitor the status of patients admitted to departments of pulmonary medicine, arterial blood gas and acid-base status must be assessed frequently which requires repeated arterial punctures. The use of arterial punctures is associated with a risk of side effects, such as pain and hematoma, and a small risk of more severe complications such as false aneurysms, ischemia, and neuropathy. ${ }^{1-4}$

Alternatives to the use of arterial blood have been investigated, including warming of the sampling site to arterialize venous blood..$^{5-7}$ Rees et al have presented a method for calculating values of arterial blood from anaerobically-taken venous samples, 
supplemented with pulse oximeter measurements of arterial oxygen saturation $\left(\mathrm{SpO}_{2}\right) .{ }^{8}$ This method mathematically transforms peripheral venous values into arterial values by simulating the transport of blood back through the tissue. The method has been shown to calculate arterial values with reasonable precision and as such is not considered to increase mortality or initiation of additional treatments. This makes the method useful for assessing blood gas and acid-base status in the vast majority of patients. ${ }^{9,10}$ Currently, no studies have explored the cost-effectiveness of such a method if applied to a pulmonary medicine department.

This study performs a cost-utility analysis (CUA), based on a Markov model, investigating whether clinical application of the venous conversion method is cost-effective when compared to the use of arterial punctures.

\section{Material and methods}

A decision analytic model was constructed to estimate the incremental cost-effectiveness ratio (ICER) of the venous conversion method as an alternative to current practice, when used at departments of pulmonary medicine. The study was based on patients suffering from chronic obstructive pulmonary disease (COPD) with acute respiratory problems, since this group of patients is the recipient of the vast majority of arterial punctures performed in pulmonary departments. The study was conducted in accordance with international guidelines and based on best available evidence. ${ }^{11}$

The economic evaluation was performed from the Danish hospital service's perspective, using the Department of Pulmonary Medicine at Aalborg Hospital, Denmark, as a reference site. The department has 25 beds, of which seven are estimated to be occupied with COPD patients with acute respiratory problems. Danish hospital statistics shows that the older COPD patients, which is the predominant group presenting at Aalborg Hospital, have an average stay of 6 days. ${ }^{12}$ In the department, 1,958 arterial punctures were performed in 2009, from which $90 \%$ were drawn from COPD patients, making it an average of 4.1 arterial punctures per patient. All prices are at 2008-2009 level (value-added tax excluded). Calculations have been made in Danish krone (Kr), with values converted to pounds sterling (£) using the exchange rate $£ 1 \mathrm{Kr}=8.6376$ (May 5th, 2010). Costs for the two methods have been calculated using average direct costs per patient, however only incremental costs have been considered.

\section{Description of the Markov model}

The Markov model represents the admission of a typical COPD patient to a department of pulmonary medicine, where two alternative methods can be used to assess the patient's blood gas and acid-base status - current clinical practice and the venous conversion method. For current clinical practice, the model assumes a chance of receiving only an arterial puncture during each day of admission until the patient is well enough to be discharged. When a patient is discharged from the hospital no further tests are performed.

The venous conversion method is defined as a combination of both venous-converted tests and arterial samples performed during the duration of patient admission. This is necessary as pulse oximetry values are essential for the venous conversion and at very low values of $\mathrm{SpO}_{2}$ these may be inaccurate, and hence require an arterial sample instead. ${ }^{13-15}$ It is conservatively appropriate that $\mathrm{SpO}_{2}$ values are very low and hence inaccurate in $10 \%$ of cases. Clinical application of the venous conversion method therefore is defined as a mixture of $90 \%$ venous-converted tests and $10 \%$ arterial samples.

For the venous conversion method there exist three Markov states, since the patient has a chance of being discharged or remaining admitted with a chance of receiving either an arterial puncture or a venous-converted test (Figure 1). The venous-converted test may replace the vast majority of arterial punctures, which was interpreted as $90 \%$ (standard deviation $[\mathrm{SD}] \pm 3 \%$ ) of all blood gas analyses being performed, whereas the rest are performed as arterial punctures. ${ }^{9,10}$ This mixture of venous-converted tests and arterial punctures is defined as the venous conversion method.

The model was constructed with a total of 11 cycles, with each cycle representing 1 day of admission, and the patients were given a $100 \%$ probability of being discharged after 10 days. The model was calibrated to reflect current practice at Aalborg Hospital so that an average patient was admitted 6 days and received 4.1 blood gas analyses. The model assumes a chance of receiving a test each day while admitted. The probability of receiving a puncture each day during admission was set to be the greatest during the first days of admission and to decrease with prolonged admission, as in accordance with clinical practice. The Markov model was built in TreeAge Pro Healthcare module 2009 (TreeAge Software Inc, Williamstown, MA).

\section{Model input}

In the model, different costs are associated with the current method and the venous conversion method. The venous conversion method requires initial investment in software and education before implementation, and the costs are therefore split into initial and incremental costs. It is expected that nurses can perform all venous-converted tests after a short 


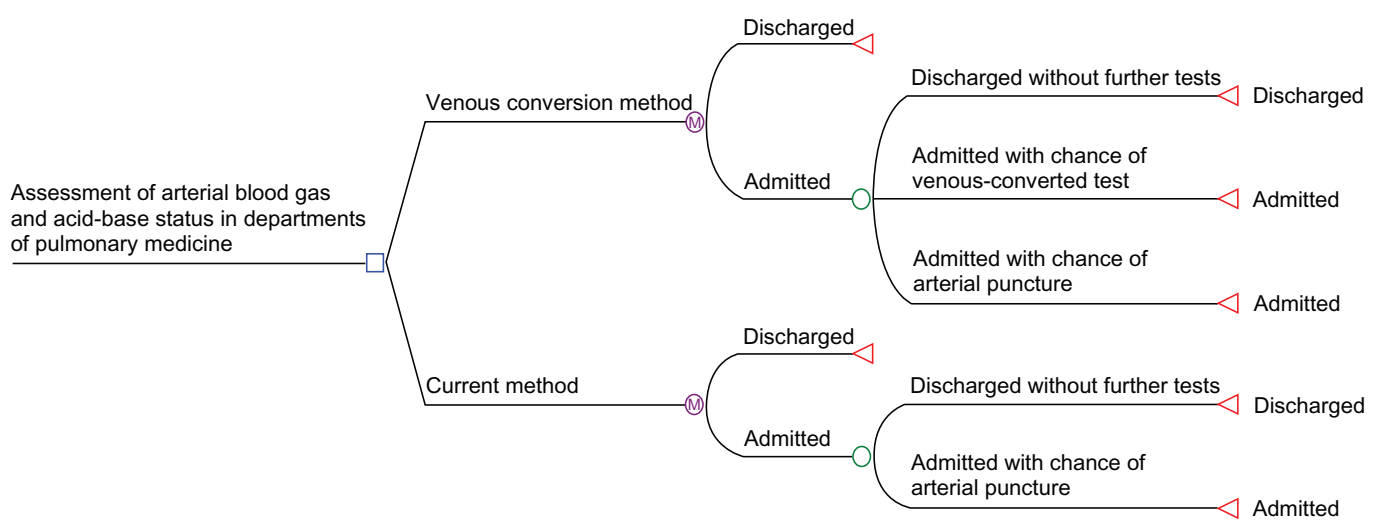

Figure I Markov model of admission to pulmonary department.

instruction, and the estimated cost of teaching nurses can be seen in Table 1. Since venous-converted tests are not yet approved for health care use, the price of a product license is an estimate. Other product licenses for the blood gas analyzer at Aalborg Hospital are priced in the range $£ 1,700-£ 4,600$, and the price of the license for the venous conversion method is therefore given an intentionally conservative estimate of $£ 4,600$ ( $S D \pm £ 1,500$ ). To account for the rapid evolution of technology, the cost of the product license is discounted using a $3 \%$ interest for 5 years. In the model it is assumed that a

Table I Model input for cost-effect and department assumptions

\begin{tabular}{|c|c|c|c|}
\hline \multicolumn{4}{|l|}{ Costs } \\
\hline Variable & EV & $\pm \mathbf{S D}$ & Ref. \\
\hline \multicolumn{4}{|l|}{ Initial costs for venous conversion method } \\
\hline Education of nurses in venous conversion method $(t)$ & 770 & 400 & Expert opinion \\
\hline Product license to blood gas analyzer $(£)$ & 4,600 & 1500 & Expert opinion \\
\hline \multicolumn{4}{|l|}{ Incremental costs } \\
\hline \multicolumn{4}{|l|}{ Time use for arterial punctures (seconds) } \\
\hline - Doctor & $360+134$ & 15 & Expert opinion \\
\hline - Nurse & $60+134$ & 15 & +3 \\
\hline - Biomedical laboratory technicians & $120+134$ & 15 & \\
\hline Time use for venous-converted tests (seconds) & & & Expert opinion \\
\hline - Nurse & $60+134$ & 15 & +3 \\
\hline \multicolumn{4}{|l|}{ Annual cost of personnel $(t)$} \\
\hline - Doctors & 69,150 & 21,380 & $\mathrm{HD}$ \\
\hline - Nurses & 41,520 & 5,810 & $\mathrm{HD}$ \\
\hline - Laboratory technicians & 42,880 & 4,790 & $\mathrm{HD}$ \\
\hline Complications per arterial puncture $(£)$ & 0.16 & 0.05 & $2,16-18$ \\
\hline Materials for arterial punctures $(\ell)$ & 0.85 & 0.08 & $H D$ \\
\hline Materials for venous-converted tests $(\ell)$ & 0.56 & 0.04 & $\mathrm{HD}$ \\
\hline \multicolumn{4}{|l|}{ Probability for extra use of materials } \\
\hline - Arterial punctures & 0.1 & 0.025 & $2,3,18$ \\
\hline - Venous punctures & 0.05 & 0.01 & 3 \\
\hline \multicolumn{4}{|l|}{ Outcome assumptions } \\
\hline Effect of a venous-converted test (QALY) & 0.00000035 & 0.00000018 & $3,21+$ expert \\
\hline Effect of an arterial puncture (QALY) & 0 & 0 & opinion \\
\hline \multicolumn{4}{|l|}{ Assumptions for midsized department } \\
\hline Arterial punctures performed* & 1958 & 100 & $\mathrm{HD}$ \\
\hline Blood gas analysis ordered & 1789 & 100 & Expert opinion \\
\hline Number of patients per year & 426 & 50 & $\mathrm{HD}$ \\
\hline \multicolumn{4}{|l|}{ Assumptions for small department } \\
\hline Arterial punctures performed* & 818 & 50 & Expert opinion \\
\hline Blood gas analysis ordered & 748 & 50 & Expert opinion \\
\hline Number of patients per year & 178 & 25 & Expert opinion \\
\hline
\end{tabular}

Note: *Includes tests redone.

Abbreviations: EV, expected value; SD, standard deviation; Ref, reference; HD, hospital database; QALY, quality-adjusted life year. 
blood gas analyzer, which is compatible with the required software for the venous conversion method, is already present at the department. The incremental costs for the venous conversion method and the current method, ie, the costs assigned each performed test, are given in Table 1.

The time spent by each group of health care professionals performing arterial punctures is estimated in correspondence with the localization of each group at Aalborg Hospital. It is assumed that nurses are situated in the department, whereas doctors and laboratory technicians are called upon whenever an arterial blood sample is required. In Table 1 this is shown with two time estimates for each group, one for walking distance and one for obtaining the sample, the latter estimate being the same for all groups. ${ }^{3}$ Whenever a doctor performs an arterial puncture, the model assumes that a nurse is also present. The model assumes that $8 \%$ of arterial punctures are performed by doctors, $59 \%$ by laboratory technicians, and $33 \%$ by nurses. Complications from performing arterial punctures, which require additional treatment, were considered an additional cost. ${ }^{16-18}$ However, the cost for severe complications has not been included in the analysis, as the incidence of severe complications occurring at Danish Hospitals was considered extremely low. By excluding severe complications from the study, the analysis becomes conservative. In addition, the possible gain in quality of life (QOL) from avoiding complications was not assessed. Furthermore, severe complications are poorly reported in the literature. ${ }^{4,19,20}$ Current prices paid by Aalborg Hospital were used as the expected values for the cost of materials for both the current and venous conversion method. All inputs used for the model are given in Table 1.

The CUA uses an estimation of quality-adjusted life years (QALYs) gained as outcome measurement, estimates of which are given in Table 1. To obtain these estimates it was necessary to evaluate the pain inflicted when performing arterial punctures compared to venous punctures. Giner et al have compared the pain perceived by patients during arterial punctures or venous punctures on a visual analog scale (VAS) of pain. ${ }^{3}$ The mean level of pain for arterial punctures was shown to be slight to moderate $(3.01 \pm 1.94 \mathrm{~cm})$, whereas only a slight pain was experienced for venous punctures $(1.80 \pm 1.10 \mathrm{~cm})$. In order to transform the incremental pain intensity during the two types of punctures into a change in QOL for the CUA, the Danish EuroQol-5 Dimension (EQ-5D) health state evaluation was used. When answering the EQ-5D questionnaire regarding pain, if answering to have moderate pain instead of no pain, the QOL is reduced by 0.062 regardless of all other answers. ${ }^{21}$ The assumption for the CUA is that arterial punctures cause the patient to go from having no pain to having moderate pain when receiving the test, and thereby reducing their QOL by 0.062 . To estimate the gain in QALYs for the CUA it is assumed that patients receiving a venous-converted test instead of an arterial puncture will have a gain in QOL of 0.062 for 3 minutes corresponding to 0.00000035 QALY $(\mathrm{SD} \pm 0.00000018$ QALY), as given in Table 1.

The Department of Pulmonary Medicine at Aalborg Hospital performs approximately 2,000 arterial punctures each year, and is therefore classified here as a midsized department. However, not all hospitals have such large departments of pulmonary medicine. Analysis was therefore also performed to calculate the costs and benefits for a smaller department performing approximately 800 per year. When performing arterial punctures some samples become contaminated with venous blood, resulting in an additional puncture being performed. Through expert opinions it was estimated that $1 / 10$ to $1 / 20$ arterial punctures must be redone. This results in a difference between performed tests and ordered tests, as seen in Table 1.

\section{Sensitivity analysis}

A probabilistic sensitivity analysis (second order Monte Carlo simulation) was conducted using a cohort of 10,000 trial simulations for both a midsized department and a small department. Each parameter in the model was given a reasonable range (Table 1) with a distribution function, which then was randomly drawn using the stochastic process. ${ }^{22}$ All probabilities were given beta distributions, and time consumption, costs, and QALY estimates were given gamma distributions. The results obtained from the Monte Carlo simulation were illustrated in a scatter plot distribution of ICER by plotting incremental cost along the y-axis and incremental effect along the x-axis. An acceptability curve was applied to the ICER distribution scatter plot to identify which strategy would be most cost-effective at the willingness-to-pay (WTP) thresholds of $£ 30,000$ per QALY gained. ${ }^{23}$ A dominant strategy was defined as having a lower incremental cost and a higher incremental effect. Cost-effectiveness acceptability curves (CEACs) were drawn in order to identify which method would be most cost-effective at various WTP. The CEACs show the probability that a given method will be cost-effective when the WTP is increased along the $\mathrm{x}$-axis. ${ }^{22} \mathrm{~A}$ CEAC is based on the assumption that hospitals may use different WTP limits and the CEAC therefore offers information on the cost-effectiveness of methods when altering the WTP. 


\section{Results}

Table 2 gives the results of the Monte Carlo simulations for the different department types. An estimated $£ 3.10$ ( $\mathrm{SD} \pm 1.54$ ) could be saved per admission in a midsized department, whereas in a small department there was an additional cost of $£ 0.01$ ( $\mathrm{SD} \pm 2.40$ ) per admission.

Both showed an incremental effect of 0.0000012 QALY (SD \pm 0.0000006$)$ per admission. From the Monte Carlo simulations a scatter plot of ICERs was made for both a midsized department (Figure 2A) and a small department (Figure 2B).

A one-way sensitivity analysis revealed that the number of performed arterial punctures was the parameter with greatest influence on results (data not shown).

The scatter plot text report reveals that at a WTP of $£ 30,000$ per QALY gained, the venous conversion method is $>95 \%$ cost-effective in a midsized department and $51 \%$ in a small department. Monte Carlo simulation of the ICER for a small department had a mean of $£ 10,645$ per QALY gained. A CEAC was plotted to illustrate the venous conversion method's probability of being cost-effective at various WTP (Figure 3).

Figure 3 illustrates the probability of the venous conversion method being cost-effective in small departments. As seen in Figure 3, it is uncertain whether the venous conversion method is cost-effective in small departments, which is particularly due to the fewer samples performed.

The results therefore clearly show the advantage of large scale use of the venous conversion method.

\section{Discussion}

The results show that the venous conversion method is a cost-effective way to assess patient blood gas and acidbase status in pulmonary departments if the ward is of a sufficient size. The CUA performed in this study showed

Table 2 Main results of probabilistic sensitivity analysis

\begin{tabular}{lll}
\hline $\begin{array}{l}\text { Monte Carlo } \\
\text { simulation } \\
\text { results for: }\end{array}$ & $\begin{array}{l}\text { Midsized } \\
\text { department }\end{array}$ & $\begin{array}{l}\text { Small } \\
\text { department }\end{array}$ \\
\hline $\begin{array}{l}\text { Incremental cost } \\
\text { per admission: }\end{array}$ & $-€ 3.10(\mathrm{SD} \pm 1.54)$ & $£ 0.0 \mathrm{I}(\mathrm{SD} \pm 2.40)$ \\
$\begin{array}{l}\text { Incremental effect } \\
\text { per admission: }\end{array}$ & $0.0000012 \mathrm{QALY}$ & $0.0000012 \mathrm{QALY}$ \\
$\begin{array}{l}\text { ICER } \\
\text { Percentage cost-effective }\end{array}$ & $>0.0000006)$ & $(\mathrm{SD} \pm 0.0000006)$ \\
at a WTP of $£ 30,000$ & & $£ 10,645$ \\
per QALY gained & & $51 \%$ \\
\hline
\end{tabular}

Abbreviations: SD, standard deviation; ICER incremental cost-effectiveness ratio WTP, willingness-to-pay; QALY, quality adjusted life year. that the venous conversion method is expected to be a dominant strategy in a midsized department, and is $>95 \%$ cost-effective at a WTP of $£ 30,000$ per QALY gained compared to $51 \%$ cost-effective in a small department. In small departments, fewer arterial punctures are performed each year causing the venous conversion method to be less likely to be cost-effective at a WTP of $£ 30,000$. The estimates for a small department in this study can therefore be viewed as a lower limit for the number of samples performed each year, because in smaller departments the venous conversion method would not be the most cost-effective option. The venous conversion method therefore holds great potential for larger departments performing numerous arterial punctures annually. The method may also have potential in other departments where arterial blood sampling is performed via needle puncture, for example, in departments of emergency medicine where arterial blood gas measurement is common in patients presenting with respiratory complications and where venous blood is sampled in many patients but seldom used for blood gas analysis. Indeed, by synchronizing venous blood gas and other routinely taken venous blood samples, it may be possible to reduce the number of venous punctures required, thereby increasing the cost-effectiveness of the method.

Several limitations exist in this analysis. A blood gas analyzer which supports the software is a requirement, and purchase of new equipment solely to support the method is unlikely to be cost effective. The study estimated an increase in QOL of 0.062 for 3 minutes per venous-converted test to quantify the less painful venous puncture when compared to arterial. The use of QALYs as a measure in acute conditions has been questioned $;{ }^{24}$ however QALYs are often considered the main health outcome measure when investigating the cost-effectiveness of new interventions. ${ }^{23}$ Clearly, when performing arterial punctures the patient is exposed to pain and thereby the QOL is temporarily reduced, even though completion of the test only takes a few minutes. Only the change in QOL due to pain has been accounted for in this study; however it should not be underestimated that other factors may affect QOL. COPD patients often receive multiple tests, and the awareness of forthcoming pain may also lead to anxiety and general discomfort for these patients, which may lead to a further lowering of QOL. In addition, by avoiding all types of complications from arterial punctures, the QOL for some COPD patients will be increased further. This provides further proof that the QOL changes during arterial sampling, and thereby a 

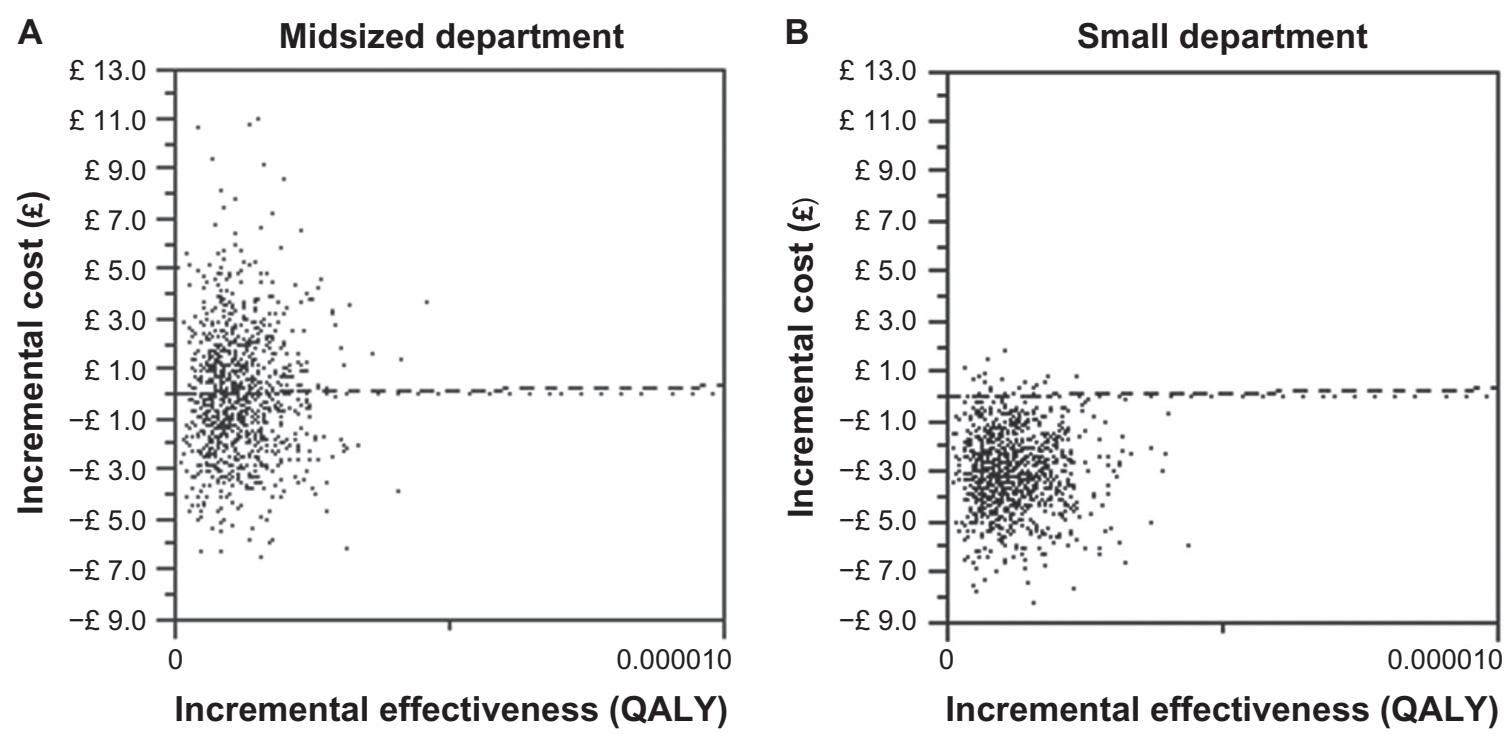

Figure 2 Incremental cost-effectiveness ratio scatterplots for midsized and small departments.

QALY gain is present, regardless of the uncertainty in the measurement of the gain in QOL.

Assumptions made as part of the analysis have intentionally been conservative, and there may be additional costbenefit from use of the venous conversion method. The initial cost of the license, assumed to be $£ 4,600$, is an estimate in the higher range of the usual prices for software updates to medical devices. Arterial punctures also include minor risk of severe complications such as ischemia, neuropathy,

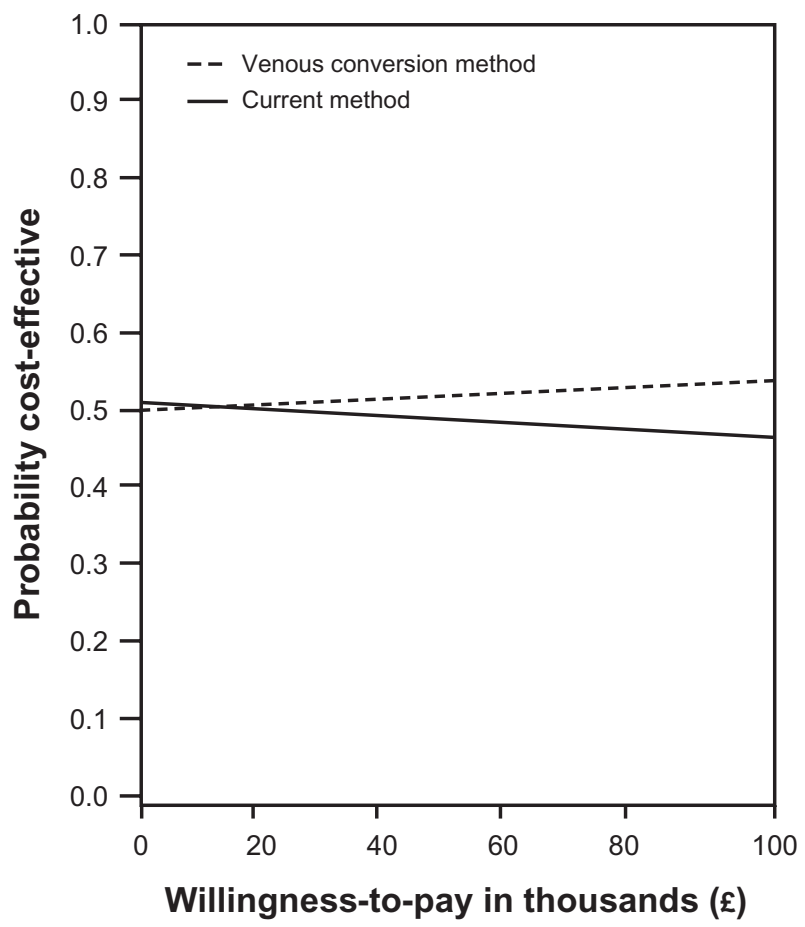

Figure 3 Cost-effectiveness acceptability curves for a small pulmonary department. and false aneurysms. ${ }^{4,19,20}$ Quantification of the incidence of severe complications is poorly reported in the literature and it was therefore excluded in the analysis. Including it would provide additional cost-benefit for the venous conversion method.

\section{Conclusion}

It is concluded that the venous conversion method should be applied to hospitals with midsized pulmonary departments, and could be applied to small pulmonary departments if the WTP is sufficient.

\section{Acknowledgments}

We thank Mikkel Troels Rasmussen and Rasmus Hogreffe Sørensen, who assisted in data collection.

\section{Disclosure}

Stephen E Rees is a board member and shareholder of OBI ApS, who hold a patent on the venous to arterial conversion method.

\section{References}

1. Berger A. Brachial artery puncture: the need for caution. J Fam Pract. 1989;28(6):720-721.

2. Gillies ID, Morgan M, Sykes MK, Brown AE, Jones NO. The nature and incidence of complications of peripheral arterial puncture. Anaesthesia. 1979;34(5):506-509.

3. Giner J, Casan P, Belda J, Gonzalez M, Miralda RM, Sanchis J. Pain during arterial puncture. Chest. 1996;110(6):1443-1445.

4. McCready RA, Hyde GL, Bivins BA, Hagihara PF. Brachial artery puncture: a definite risk to the hand. South Med J. 1984;77(6):786-789.

5. Pitkin AD, Roberts CM, Wedzicha JA. Arterialised earlobe blood gas analysis: an underused technique. Thorax. 1994;49(4):364-366. 
6. Zavorsky GS, Cao J, Mayo NE, Gabbay R, Murias JM. Arterial versus capillary blood gases: a meta-analysis. Respir Physiol Neurobiol. 2007;155(3):268-279.

7. Zello GA, Smith JM, Pencharz PB, Ball RO. Development of a heating device for sampling arterialized venous blood from a hand vein. Ann Clin Biochem. 1990;27(Pt 4):366-372.

8. Rees SE, Toftegaard M, Andreassen S. A method for calculation of arterial acid-base and blood gas status from measurements in the peripheral venous blood. Comput Methods Programs Biomed. 2006; 81(1):18-25.

9. Rees SE, Hansen A, Toftegaard M, Pedersen J, Kristiensen SR, Harving H. Converting venous acid-base and oxygen status to arterial in patients with lung disease. Eur Respir J. 2009;33(5):1141-1147.

10. Toftegaard M, Rees SE, Andreassen S. Evaluation of a method for converting venous values of acid-base and oxygenation status to arterial values. Emerg Med J. 2009;26(4):268-272.

11. Drummond MF, Sculpher MJ, Torrance GW, O’Brien BJ, Stoddart GL. Methods for the Economic Evaluation of Health Care Programmes. 3rd ed. Oxford, UK: Oxford University Press; 2005.

12. National Board of Health. Visual DkDRG. 2010 Feb 2. Available from: http://visualdkdrg.sst.dk/2007/. Accessed Aug 302010.

13. Kolb JC, Farran P, Norris SR, Smith D, Mester J. Validation of pulse oximetry during progressive normobaric hypoxia utilizing a portable chamber. Can J Appl Physiol. 2004;29(1):3-15.

14. van de Louw A, Cracco C, Cerf C, et al. Accuracy of pulse oximetry in the intensive care unit. Intensive Care Med. 2001;27(10):1606-1613.

15. Wouters PF, Gehring H, Meyfroidt G, et al. Accuracy of pulse oximeters: the European multi-center trial. Anesth Analg. 2008; 94 Suppl 1:S13-S16.
16. Ankjaer-Jensen A, Rosling P, Bilde L. Variable prospective financing in the Danish hospital sector and the development of a Danish case-mix system. Health Care Manag Sci. 2006;9(3):259-268.

17. National Board of Health. DAGS rates for outpatient clinics (2009). 2010 Jan 11. Available from: http://www.sum.dk/Sundhed/DRGsystemet/Takster/2009.aspx Accessed Aug 302010.

18. Okeson GC, Wulbrecht PH. The safety of brachial artery puncture for arterial blood sampling. Chest. 1998;114(3):748-751.

19. Luce EA, Futrell JW, Wilgis EF, Hoopes JE. Compression neuropathy following brachial arterial puncture in anticoagulated patients. J Trauma. 1976;16(9):717-721.

20. Matsagas MI, Mitsis M, Rigopoulos C, et al. A large radial artery false aneurysm after repeated arterial punctures, causing compartment syndrome of the forearm. Intensive Care Med. 2003; 29(6):1032.

21. Wittrup-Jensen KU, Lauridsen J, Gudex C, Pedersen KM. Generation of a Danish TTO value set for EQ-5D health states. Scand J Public Health. 2009;37(5):459-466.

22. Fox-Rushby J, Cairns J, editors. Economic Evaluation. Maidenhead, UK: Open University Press; 2005.

23. National Institute for Health and Clinical Excellence. Social value judgements: principles for the development of NICE guidance. 2010 Feb 11. Available from: http://www.nice.org.uk/media/C18/30/ SVJ2PUBLICATION2008.pdf. Accessed Aug 302010.

24. Bala MV, Zarkin GA. Are QALYs an appropriate measure for valuing morbidity in acute diseases? Health Econ. 2000;9(2):177-180.
ClinicoEconomics and Outcomes Research

\section{Publish your work in this journal}

ClinicoEconomics \& Outcomes Research is an international, peerreviewed open-access journal focusing on Health Technology Assessment, Pharmacoeconomics and Outcomes Research in the areas of diagnosis, medical devices, and clinical, surgical and pharmacological intervention. The economic impact of health policy and health systems

\section{Dovepress}

organization also constitute important areas of coverage. The manuscript management system is completely online and includes a very quick and fair peer-review system, which is all easy to use. Visit http://www.dovepress.com/testimonials.php to read real quotes from published authors. 